\title{
Double Jeopardy: Race/Ethnicity and Sexual Harassment in the U.S. Military*
}

\author{
Richard J. Harris, Ph.D. \\ Department of Social Work, University of Texas at San Antonio \\ 501 West Durango Blvd. San Antonio, TX 78207 \\ Email: Richard.harris@utsa.edu \\ Justin D. Hackett, Ph.D. (Corresponding author) \\ Department of Social Sciences, University of Houston-Downtown \\ 1 Main Street Houston, TX 77002
}

Tel: 713-221-8961Ｅmail: hackettj@uhd.edu

Juanita M. Firestone, Ph.D.

Department of Criminal Justice, University of Texas at San Antonio, San Antonio, TX 78209

501 West Durango Blvd. San Antonio, TX 78207

Email: Juanita.Firestone@utsa.edu

*The views expressed here are those of the authors and should not be attributed to the Department of Defense.

Received: June 09, 2011 Accepted: June 19, 2011 DOI: 10.5296/jpag.v1i1.708

\begin{abstract}
Our research examines a sample of respondents from a Department of Defense (DoD) survey in an attempt to determine the incidence of sexual harassment in the military by race/ethnic category and to determine whether or not women's experiences differ based on race and ethnic membership. Logistic regression is used to test whether racial and ethnic minorities face double risks of victimization with respect to sexual Results do not support an adverse interaction of race and gender with respect to sexual harassment in the military for Black women; however, findings varied depending on type of harassment for Hispanic and Other
\end{abstract}


Race women. The biggest surprise is that the males report a higher incidence of harassment in 2002. Replicating an earlier finding, when no environmental harassment is reported individual harassment is very rare. Overall, this finding supports the importance of organizational context in producing different levels of harassment.

Keywords: Sexual harassment, Race, Ethnicity, Sex, Military.

\section{Introduction}

Over the past decade and a half sexual harassment of women in the workplace has received considerable media, academic and legal attention. Furthermore, historical accounts as well as recent reports agree that sexual harassment was and continues to be a persistent, costly problem in the workplace, including the U.S. military (Bularzik, 1978; Safran, 1976; U.S. Merit Systems Protection Board, 1981; 1988; Firestone and Harris, 1999; Firestone and Harris, 2003; Newman, Jackson and Baker, 2003; Jackson and Newman, 2004; Uggen and Blackstone, 2004). While sexual harassment has typically been defined only in terms of gender, the problem could be complicated by racism, which can leave women of color at greater risk of being targets and leave them with even fewer options than white women ${ }^{\mathrm{i}}$. Some of these complications surfaced during the Clarence Thomas hearings. While many white women rallied to Hill's defense, many African-American women did not feel comfortable siding with white women against a black man, even though Anita Hill is black (Colasti \& Karg, 1992).

The prevailing expectation has been that women of color face even greater problems with sexual harassment than white women (Fain \& Anderton, 1987; Gruber \& Bjorn, 1986; Murrell, 1996), and that they are more likely to be harassed by white men than by men of their own race (Murrell, 1996). However, very little generalizable evidence is available to support the concept "double jeopardy" in sexual harassment hypotheses (see Harris \& Firestone, 1996, for an empirical test). In surveys conducted for the U.S. Navy in 1989, 1991, and 1993, black women were less likely than white and Hispanic women to report harassment experiences (Culbertson, et al., 1992; Culbertson, Rosenfeld \& Newell, 1993; Thomas, Newell \& Eliassen, 1995). This study uses data from one of the large-scale efforts to assess the prevalence of sexual harassment in the U.S. military, the Armed Forces 2002 Sexual Harassment Survey, providing the opportunity to test the hypothesis in a large organization (see, Lipari \& Lancaster, 2003).

\subsection{Double Risk: The Interaction of Race and Gender}

Because gender stereotypes are not uniform across all racial groups, the experiences of minority women have been and continue to be attributed to interactions between race and gender (see for example, Almquist, 1975; 1979; King, 1988; O’Connell, 1996; Ryff, Keyes \& Hughes, 2003; Roman, 2004; Farmer \& Ferraro, 2005). Researchers in a variety of disciplines including sociology, demography, economics and management refer to this interaction as "double jeopardy"ii (Bell, Denton and Nkomo, 1993; Foegen, 1992; Malveaux \& Wallace, 1987; Smith \& Waitzman, 1994; Segura, 1992). Thus, the term "double jeopardy," reflects discrimination as women and as members of racial and/or ethnic minority groups. 
Definitions of sexual harassment in the workplace often focus on power differences between the harasser and the individual harassed. This focus on power differences within an organization suggests that the double burden of sexism and racism would mean that minority women would experience more harassment than that expected based on the additive effects of gender and race separately.

Research conducted after the initial integration of women into the military suggested that the women who served may have been insulated from at least some of the economic vulnerability of civilian women. Butler and Brewer (1978), for example, found no systematic differences between enlisted men and women with respect to promotion rates. Later works, however, discovered problems, which suggest that women are more vulnerable to discrimination than are men. For example, Thomas (1987) found negative bias in the evaluations of women in the Navy, and Stewart and Firestone (1992) found somewhat lower retention rates for women officers compared to men across all services. The later studies are suggestive of the type of vulnerability that often accompanies sexual harassment.

While black women brought a disproportionate number of the early harassment lawsuits (Colasti \& Karg, 1992), several surveys conducted for the U.S. Navy found that black women officially reported the lowest amount of harassment among white, black and Hispanic women included in the analysis, and that black and Hispanic women were not harassed (whether reported or not) more than white women (Culbertson, et al., 1992; Culbertson, Rosenfeld \& Newell, 1993; Thomas, Newell \& Eliassen, 1995). These findings were supported by initial analysis of the Department of Defense survey by Niebuher and Boyles (1991).

Our research examines a sample of respondents from a DoD-wide survey in an attempt to determine the incidence of sexual harassment in the military by race/ethnic category and to determine whether or not women's experiences differ based on race and ethnic membership.

\subsection{Sexual Harassment}

Since Farley's (1978) and MacKinnon's (1979) groundbreaking books, the key concepts in describing harassing behavior continue to be uninvited and unwanted. Most organizations use the U.S. Office of Personnel management policy statement as the model for defining sexual harassment. In 1980 the initial definition was expanded to include any conduct of a sexual nature which created "an intimidating, hostile, or offensive working environment" (reported in U.S. Merit Systems Protection Board, 1988, p. 2). Some consider this definition broad enough so that conceptual, empirical and theoretical inconsistencies arising from specific studies remain unresolved (Uggen \& Blackstone, 2004).

Virtually any behavior, including requests for dates, pressure for sexual activities, comments, jokes, and attempted and forcible rape can constitute sexual harassment. However, individual definitions of these behaviors as sexual harassment vary systematically depending on individual characteristics as well as specific contexts in which the behavior occurred. Thus, whether a behavior is defined as harassment depends on such factors as the status differences of the individuals involved, how often the behavior occurred, whether the individuals involved have dated previously, and whether the target is perceived as having 
behaved suggestively (Uggen \& Blackstone, 2004; Thomas, 1995; Fitzgerald, 1990; Fitzgerald \& Shullman, 1993; Pryor, 1985). While sexual harassment appears highly subjective, and the experiences of women and men seem variable and open to alternative explanations (Gordon, 1981), in fact individuals do attempt to discriminate between behaviors which may be defined as offensive and those defined as harassment. On the other hand, lack of objective information about the situation seems to leave individuals with a certain amount of ambivalence as to whether specific behaviors should be defined as inappropriate, serious, and offensive enough to be labeled harassment (Uggen \& Blackstone, 2004; Fitzgerald \& Shullman, 1993; Thomas, 1995).

This latter subjective understanding may be influenced by the race of the individuals involved. For example, Staples (1994) argued that "prevailing definitions of sexual harassment are in conflict with traditional Black dating styles." Thus Staples implies that African American women may place behaviors classified as sexual harassment by women of other races within a context of cultural courtship style and be less likely to take offense. In addition, Giuffre and Williams (1997) found through ethnographic research that in the occupation of waiting tables respondents were more likely to label behavior as sexual harassment if the harasser was someone of a different race or ethnicity.

\subsection{Models of Sexual Harassment}

In general, one of three explanatory models is used to understand workplace harassment (see, Tangri, Burt \& Johnson, 1982; Terpstra \& Baker, 1986). Biological or "natural” perspectives suggest that sexual harassment results from the natural attraction between men and women. Within this framework sexual behaviors in the workplace are defined as typical. However, some individuals fail to distinguish between mutual attraction and the imposition of unwanted, uninvited behaviors. This view often defines harassers as atypical when compared to normal people (i.e. "sick") and denies any systematic patterns of sexual harassment.

A second set of explanations maintains that organizations provide the opportunity structures that perpetuate sexual harassment (DiTomaso, 1989; Fain \& Anderton, 1987; Gruber \& Bjorn, 1986; Kanter, 1977; Konrad \& Gutek, 1986). In other words, individuals use their structural positions within an organizational system to compel others to provide sexual gratification. Under such a scenario, women and minority women in particular, are likely victims of harassment because they typically have less organizational power than men. Specific organizational characteristics such as type of technology, worker proximity, sex ratios, availability of grievance procedures, etc. may also moderate the extent of harassing behaviors (Gruber \& Bjorn, 1986; Gutek \& Morasch, 1982; Kanter, 1977; Cockburn, 1991). As a result, policies regarding sexual harassment tend to be organization specific. The U.S. military offers a good example of this problem. One finding of the Report of the Task Force on Women in the Military (January 1988) included difficulty in assessment of the extent of sexual harassment because each service branch keeps separate statistics and has different policies regarding grievances. Lack of consistency in policies across organizations could also aggravate enforcement problems. Zimmerman’s (1995) scathing description of military 
women's experiences in the wake of the "Tailhook" scandal highlighted the importance of the history and environment of the Navy in contributing to the acceptance of such harassment as "normal." Her prediction that the scandal would ultimately necessitate profound structural changes to prevent further sordid harassment incidents seems to have come to pass. Since 1988, the military has engaged in systematically collecting service-wide data on the prevalence of harassment experiences, perceptions about harassment events, the context of such events as well as tolerance of harassment by peers and supervisors.

Socio-cultural models predict that learned sex role behaviors (i.e. gender rather than biological sex) define predictable patterns of harassment based on differential distributions of power and status between men and women (e.g., Farley, 1978; Frug, 1992; Gutek \& Morasch, 1982; MacKinnon, 1979; Konrad \& Gutek, 1986) or conditioning processes which encourage individual men to act aggressively and individual women to act submissively (see Pryor, 1985; 1987; Terpstra \& Baker, 1986). In other words harassment results from socialization pressures which "teach" men and women different attitudes and behaviors. Men and women learn to manage interactions according to accepted gender norms, and these learned behaviors "spill over” into the workplace (Gutek \& Morasch, 1982). In a similar manner, individuals may bring racial stereotypes into the workplace. In the case of women of color, gender and racial stereotypes may interact to compound individual experiences including those of sexual harassment.

\section{Methods}

\subsection{Participants and Procedure}

The "Armed Forces 2002 Sexual Harassment Survey," (Lipari \& Lancaster, 2003) conducted for the Office of the Secretary of Defense by the Defense Manpower Data Center, provides the data base for this analysis. This was a "worldwide scientific survey of how men and women work together in the ... Active-duty Military Services ..." The stated purpose of the survey was" To assess the prevalence of sexual harassment and other unprofessional, gender-related behaviors...." (Lipari \& Lancaster, 2003, p. 6). The instrument "was based on the 1995 Form B questionnaire and incorporated further psychometric and theoretical advances in sexual harassment research” (Lipari \& Lancaster, 2003, p. 6).

A single-stage, stratified random sample of 60,415 respondents was drawn for the survey, representing male and female enlisted personnel and officers in the Army, Navy, Marines, Air Force and Coast Guard. Data were collected by mail and via the Web, with one-third of respondents returning responses via the internet. A total of 19,960 usable surveys were returned for a response rate of $36 \%$, though not all of these respondents answered the questions related to sexual harassment (see, Flores-Cervantes, Valiant, Harding and Bell, 2003). The original sample includes 10,235 males and 9,725 females, illustrating the oversampling of women. The sampling frame was stratified by service branch, sex, paygrade, race/ethnicity, likelihood of deployment and geographic location (Elig, 2003). A series of weighting schemes was developed by the original survey team at the Defense Manpower Data Center (2003) tied to branch of service, rank, sex and race, and to test for non-response bias. The full weights provide estimated numbers of respondents that 
approximate the total active force as of December 2001 (Lipari \& Lancaster, 2003). For the analyses that follow, the full weight was divided by the mean weight, retaining estimates of the approximate total number of cases in the original survey. This procedure provides proportionate representation of respondents relative to their position in the active duty military population and allows for meaningful use of tests of statistical significance. To illustrate the impact of the weighting, there are 16,154 weighted male respondents $(84.8 \%)$ and 2,906 weighted female respondents (15.2\%), for a total of 19,060 weighted cases.

Due to the large number of cases, all relationships from the cross-tabular analyses presented are statistically significant based on the chi-square statistic. The double jeopardy concept requires a multivariate analysis framework to test for statistical interactions between race/ethnic minority status and gender, controlling for other possible independent variables. Logistic regression is used for this purpose because the dependent variables are dichotomous measures of whether or not the respondents report themselves to have been sexually harassed. Three dependent variables are analyzed -- whether or not the respondents report experiencing any harassment in the military, environmental harassment, or individual harassment (see Firestone \& Harris, 1994; Harris \& Firestone, 1997). Those harassment behaviors categorized as individual reflect demands on the target, while those designated environmental are indicative of a potentially hostile or intimidating work setting. The logistic regression coefficients represent the change in the log of the odds of reporting harassment associated with a unit change in an independent variable, controlling for the influence of the other independent variables in the analysis. The Wald statistic, with a chi-square distribution for large samples, is used to test the possibility that the logistic coefficients are significantly different from zero. $\mathrm{R}$, a transformation of the Wald statistic, measures the partial correlation between dependent and independent variables, and is used to identify the relative importance of the independent variables (see Norusis, 1990).

The analysis will describe the reported experiences of the respondents overall by race and ethnicity and gender, and then test for interactions between race and ethnicity and other variables controlling for rank, marital status and service. Finally, race/ethnicity of respondent will be examined in relation to the reported race of the alleged offender(s).

\subsection{Measures}

The survey furnished detailed set of statements from which the respondents could evaluate conditions in the work site, including a set of questions which ask them "about sex/gender related talk and/or behavior that was unwanted, uninvited, and in which [the respondent] did no participate willingly” (DMDC, 2003, p. 10). Based on these latter statements, we identified individualistic forms of sexual harassment that are personal and frequently directly physical in nature, and leave little room for misinterpretation by either the victim or the perpetrator (sexual assault, touching, sexual phone calls). This form can be differentiated from a broader category of more public, environmental harassment (jokes, whistles, suggestive looks). The latter actions can be experienced even if directed at another individual, and are ambiguous enough to leave their interpretation dependent on the environmental context. ${ }^{\text {iii }}$ Respondents were classified as having experienced individualistic or 
environmental unwanted, uninvited sexual behavior, or any form (individualistic, environmental, or both).

Nineteen behaviorally based statements were used to "represent a continuum of unprofessional, gender-related behaviors---not just sexual harassment---...” (Lipari \& Lancaster, 2003: Appendix (Tab) 4). The responses were a scale measuring frequency incidents occurred ranging from "never" to "very often." Clearly the respondents were provided with a framework that would allow them to make meaningful and reasonably comprehensive judgments about conditions in the work place. The specificity of the list and the questionnaire format means that individuals were reporting about behaviors that they had experienced in the past 12 months, and that they defined as unwanted and uninvited, rather than offering more general statements about whether they had experienced any sexual harassment in general.

The data also allow us to compare harassment experiences based on within group and cross group relationships. In other words, we can determine the likelihood that women of color are more likely to be harassed than white women, and whether harassment is likely to occur by members of the same or a different race/ethnic group.

Finally, those reporting harassment within the last twelve months were asked which of the incidents had the greatest effect on them as well as a series of questions about the context of that incident and their response to it. While this tiered format allows for detailed analysis of those reporting harassment, it does not allow for predicting harassment because those not harassed were not asked the same questions about organizations context.

\section{Results}

Table 1 provides a quick comparison of results from the 2002 survey with those obtained in earlier analyses of the 1988 and 1995 surveys. Ever and Individual harassment showed a continued pattern of decline for women (though well over half report some harassment in the last 12 months). However, there was a slight increase in Environmental Harassment. In striking contrast, males report substantially higher levels of harassment for all three measures. It is not clear (yet) if this is partly due to changes in measurement approaches. We will reanalyze the 1995 data to verify the pattern reported here, comparing results from Form A and Form B survey instruments. 
Table 1: $\quad$ Reported Harassment by Type Over Time

\begin{tabular}{|cccc|}
\multicolumn{1}{c}{} & Ever & Individual & Environmental \\
\cline { 2 - 3 } 1988 & & Female & \\
1995 & 73.3 & 54.6 & 66.2 \\
2002 & 59.1 & 39.3 & 49.4 \\
& 55.8 & 36.3 & 51.9 \\
1988 & & Male & \\
1995 & 18.6 & 12.4 & 16.4 \\
2002 & 11.7 & 7.1 & 9.6 \\
& 27.7 & 12.7 & 25.2 \\
1988 & & Total & \\
1995 & 24.0 & 16.5 & 21.4 \\
2002 & 17.2 & 11.0 & 14.5 \\
\cline { 3 - 3 } & 32.0 & 16.3 & 29.2 \\
\hline
\end{tabular}

Sources: Data for 1988 and 1995 taken from Firestone and Harris (1999), data for 2002 tabulated from the $2002 \mathrm{DoD}$ survey data file.

Table 2 presents basic information on the percentages of males and females reporting harassment experiences Ever, Individually and Environmentally by race and ethnicity. Overall, well over 27 percent of the men and well over 55 percent of the women report sexual harassment. Environmental Harassment appears to be somewhat more prevalent than Individual Harassment, but both are pervasive for women. Among the men, the Hispanic, Black, and Other categories report significantly higher levels of ever having been harassed. However, the percentages for those classified as Black, Hispanic or White are all very similar. This overall pattern for males is essentially the same for the reports of environmental harassment, with the exception that Blacks and Whites have the same lower value of $11.7 \%$ for individual harassment.

The most prominent finding for the women is the much higher levels of reported harassment. The pattern by race and ethnicity is not at all similar to that for the men. Basically, black women appear to be significantly less likely to report having experienced sexual harassment. 
Table (2): Harassment in the Military by Race and Ethnicity

\begin{tabular}{|c|c|c|c|c|c|c|c|c|}
\hline & \multicolumn{2}{|c|}{ Overall Harassment } & \multicolumn{2}{|c|}{ Individual Harassment } & \multicolumn{2}{|c|}{ Environmental Harassment } & \multirow{2}{*}{$\begin{array}{c}\text { Total N: } \\
\text { Males }\end{array}$} & \multirow{2}{*}{$\begin{array}{l}\text { Total N: } \\
\text { Females }\end{array}$} \\
\hline & Male & Female & Male & Female & Male & Female & & \\
\hline & 31.0 & 58.6 & 16.6 & 39.5 & 27.8 & 54.1 & & \\
\hline Hispanic & 556 & 187 & 298 & 126 & 499 & 173 & 1794 & 319 \\
\hline \multicolumn{9}{|l|}{ White } \\
\hline \multirow[t]{2}{*}{$(\mathrm{NH})$} & 26.6 & 58.7 & 11.7 & 36.0 & 24.2 & 55.1 & & \\
\hline & 2702 & 836 & 1195 & 512 & 2464 & 785 & 10174 & 1424 \\
\hline \multirow[t]{2}{*}{ Black (NH) } & 28.5 & 49.1 & 11.7 & 31.3 & 26.1 & 45.9 & & \\
\hline & 760 & 432 & 311 & 275 & 696 & 404 & 2667 & 880 \\
\hline \multirow[t]{2}{*}{ Other $(\mathrm{NH})$} & 29.0 & 56.4 & 13.7 & 39.4 & 26.9 & 51.6 & & \\
\hline & 440 & 159 & 207 & 111 & 407 & 145 & 1515 & 282 \\
\hline \multirow[t]{2}{*}{ Total } & 27.6 & 55.6 & 12.4 & 35.2 & 25.2 & 51.9 & & \\
\hline & 4458 & 1614 & 2011 & 1024 & 4066 & 1507 & 16150 & 2905 \\
\hline
\end{tabular}

Table 3 presents the results of logistic regression analyses designed to test the impact of race and ethnicity controlling for rank, marital status, and branch of service. Additionally, tests for the possibility of interaction effects between race/ethnicity, gender and rank provide the most direct exploration of the possibility of double jeopardy influences. As shown in the table, all three equations (Ever, Environmental and Individual harassment) have significant model Chi-square values and correctly predict substantial proportions of the respondents' harassment reports. Respondents with a predicted value of 0.5 or higher are classified as being in the "harassed" group, while those with a lower value are classified as "not harassed."

Not surprisingly, based on the earlier results, gender emerges as the dominant variable in these equations, with females much more likely to report harassment experiences. The fact that other variables have statistically significant coefficients, independent of the influence of gender, is important. First term enlisted is the second (or tied for second) most influential variable in each equation. In terms of race and ethnicity, Hispanics report themselves to be more likely to experience harassment in all three equations. The coefficient for Black is positive and significant only for overall harassment, and for environmental harassment using a one-tailed test. There is no significant relationship with "Other" race in any of the models. Those married are significantly less likely to report ever having been harassed. The Army and Navy are significantly more likely to have reports of harassment, even controlling for the other variables. In fact, being in the Navy is the third most important variable (tied for second in the Environmental equation) in each equation and being in the Army is close.

Few of the interaction variables are statistically significant. Strikingly after controlling for the other variables, Black females are significantly less likely to report overall and environmental harassment, but this interaction term is not significantly related to individual harassment. Hispanic females are less likely to report environmental sexual harassment (one-tailed test), but the coefficient is not significantly related to overall or individual 
harassment.

Table (3): Logistic Regression Analyses of Harassment in the Military

Overall Harassment

Individual Harassment

Environmental Harassment

\begin{tabular}{|c|c|c|c|c|c|c|c|c|c|c|c|c|}
\hline & Coeff. & S.E. & $\operatorname{Exp}(B)$ & $\mathrm{R}$ & Coeff. & S.E. & $\operatorname{Exp}(B)$ & $\mathrm{R}$ & Coeff. & S.E. & $\operatorname{Exp}(B)$ & $\mathrm{R}$ \\
\hline Female & $1.36^{* * *}$ & 0.07 & 3.89 & 0.13 & $1.43^{* * *}$ & 0.07 & 4.18 & 0.16 & $1.34^{* * *}$ & 0.07 & 3.84 & 0.13 \\
\hline Black & $0.10 *$ & 0.05 & 1.10 & 0.01 & -0.01 & 0.07 & 0.99 & 0.00 & $0.09 \dagger$ & 0.05 & 1.10 & 0.01 \\
\hline Hispanic & $0.15^{*}$ & 0.06 & 1.17 & 0.01 & $0.26 * * *$ & 0.07 & 1.30 & 0.02 & $0.14^{*}$ & 0.06 & 1.15 & 0.01 \\
\hline Other & 0.09 & 0.06 & 1.09 & 0.00 & 0.07 & 0.08 & 1.07 & 0.00 & 0.11 & 0.07 & 1.11 & 0.01 \\
\hline Officer & $-0.13^{*}$ & 0.06 & 0.88 & 0.01 & $-0.74 * * *$ & 0.11 & 0.48 & 0.05 & -0.09 & 0.06 & 0.91 & 0.00 \\
\hline First Enlist. & $0.31^{* * *}$ & 0.04 & 1.36 & 0.05 & $0.51^{* * *}$ & 0.05 & 1.66 & 0.08 & $0.26 * * *$ & 0.04 & 1.29 & 0.04 \\
\hline Married & $-0.23^{* * *}$ & 0.04 & 0.79 & 0.04 & $-0.45^{* * *}$ & 0.05 & 0.64 & 0.08 & $-0.18^{* * *}$ & 0.04 & 0.83 & 0.03 \\
\hline Army & $0.23^{* * *}$ & 0.04 & 1.26 & 0.03 & $0.22^{* * *}$ & 0.06 & 1.25 & 0.03 & $0.26^{* * *}$ & 0.04 & 1.30 & 0.04 \\
\hline Navy & $0.26 * * *$ & 0.05 & 1.29 & 0.04 & $0.34 * * *$ & 0.06 & 1.41 & 0.04 & $0.28 * * *$ & 0.05 & 1.32 & 0.04 \\
\hline Marines & $0.10 \dagger$ & 0.06 & 1.11 & 0.01 & $0.27^{* * *}$ & 0.07 & 1.31 & 0.03 & 0.07 & 0.06 & 1.08 & 0.00 \\
\hline Coast Guard & $0.42 * * *$ & 0.10 & 1.53 & 0.03 & $0.23 \dagger$ & 0.14 & 1.26 & 0.01 & $0.46^{* * *}$ & 0.10 & 1.58 & 0.03 \\
\hline Female Officer & 0.02 & 0.15 & 1.02 & 0.00 & 0.18 & 0.19 & 1.19 & 0.00 & -0.01 & 0.15 & 0.99 & 0.00 \\
\hline Black Female & $-0.53 * * *$ & 0.11 & 0.59 & 0.03 & $-0.29 *$ & 0.12 & 0.75 & 0.01 & $-0.51 * * *$ & 0.11 & 0.60 & 0.03 \\
\hline Hispanic Female & -0.24 & 0.15 & 0.79 & 0.00 & -0.25 & 0.16 & 0.78 & 0.01 & $-0.25 \dagger$ & 0.15 & 0.78 & 0.01 \\
\hline Other Female & -0.21 & 0.16 & 0.81 & 0.00 & 0.03 & 0.17 & 1.03 & 0.00 & -0.26 & 0.16 & 0.77 & 0.01 \\
\hline Black Officer & 0.06 & 0.18 & 1.06 & 0.00 & -0.30 & 0.41 & 0.74 & 0.00 & 0.11 & 0.19 & 1.12 & 0.00 \\
\hline Hispanic Officer & 0.10 & 0.21 & 1.10 & 0.00 & 0.36 & 0.32 & 1.44 & 0.00 & 0.09 & 0.21 & 1.09 & 0.00 \\
\hline Other Officer & -0.11 & 0.22 & 0.90 & 0.00 & 0.07 & 0.38 & 1.07 & 0.00 & -0.11 & 0.22 & 0.90 & 0.00 \\
\hline Black Female Officer & -0.04 & 0.33 & 0.97 & 0.00 & 0.37 & 0.54 & 1.45 & 0.00 & -0.10 & 0.34 & 0.91 & 0.00 \\
\hline Hispanic Female Officer & 0.15 & 0.46 & 1.16 & 0.00 & -0.11 & 0.57 & 0.90 & 0.00 & 0.17 & 0.46 & 1.18 & 0.00 \\
\hline Other Female Officer & 0.01 & 0.42 & 1.01 & 0.00 & -0.02 & 0.56 & 0.98 & 0.00 & -0.13 & 0.42 & 0.88 & 0.00 \\
\hline Constant & -1.13 & 0.05 & 0.32 & & -2.09 & 0.06 & 0.12 & & -1.29 & 0.05 & 0.28 & \\
\hline Model Chi-Square $(\mathrm{df}=21)$ & \multicolumn{3}{|c|}{$1143.3^{* * *}$} & \multicolumn{4}{|c|}{$1473.76 * * *$} & \multicolumn{5}{|c|}{$1016.8^{* * *}$} \\
\hline Cox \& Snell R Square & \multicolumn{3}{|c|}{0.059} & \multicolumn{4}{|c|}{0.075} & \multicolumn{5}{|c|}{0.052} \\
\hline Nagelkerke R Square & \multicolumn{3}{|c|}{0.082} & \multicolumn{4}{|c|}{0.128} & \multicolumn{5}{|c|}{0.074} \\
\hline \multicolumn{13}{|l|}{ Percent Correct } \\
\hline Overall & \multicolumn{3}{|c|}{70.427} & \multicolumn{4}{|c|}{84.196} & \multicolumn{5}{|c|}{72.334} \\
\hline No Harassment & \multicolumn{3}{|c|}{93.404} & \multicolumn{4}{|c|}{98.868} & \multicolumn{5}{|c|}{94.850} \\
\hline Some Harassment & \multicolumn{3}{|c|}{21.409} & \multicolumn{4}{|c|}{6.829} & \multicolumn{4}{|c|}{17.976} & \\
\hline
\end{tabular}

Because sex of respondent is such a powerful variable in predicting the likelihood of sexual harassment experiences, Table 4 and Table 5 present logistic regression results separately for females and males. Focusing on the females first, the newly enlisted were significantly more likely to report harassment in each of the three equations, and officers were significantly less likely to report individual harassment. Along with the Army and Navy, the Marines emerge as a place where women are significantly more likely to report harassment. Black females are still significantly less likely to report sexual harassment, while the coefficients are not significant for Hispanic women. Finally, married women were 
significantly less likely to report harassment in all three equations. Being newly enlisted is the most important variable in the "Individual" equation and being in the Army is the most important variable in the "Ever" equation, while being in the Army or the Navy are tied for the most important in the "Environmental" equation.

Among the males, those who are married are the least likely to report ever being harassed, while those in the Army and Navy tend to have an increased likelihood of reporting harassment. Men in the Marines are significantly more likely to report individual harassment only. Black men are significantly more likely to report sexual ever being harassed and environmental harassment (one-tailed test) and Hispanic men are significantly more likely to report harassment in all three equations.

The findings for Blacks in Table 4 refine and clarify the findings for Black females in Table 3. Black women are less likely than White women to report harassment, but Black men are more likely to report harassment than White men. While illustrating a sex/race interaction, it is not the simple race/sex interaction expected from the double jeopardy hypothesis. The double jeopardy hypothesis only predicts that minority women would experience even more harassment than expected based solely on either their race/ethnicity or their sex.

All of the equations in Table 4 and Table 5 have significant model Chi-square values. It is striking, however, that the percentages correctly predicting some sexual harassment for the females are high -- close to $78 \%$ for those ever harassed and about $64 \%$ for the environmentally harassed equations. The prediction for individual harassment is much lower at about 20\%. These high percentages emerge, obviously, because such a large proportion of women overall report harassment experiences. The errors in prediction emerge from cases where women report no harassment. In complete contrast, the models predict that none of the men should experience any form of sexual harassment. Basically, while there are statistically significant variables influencing the probability of reporting having been sexually harassed, none of the men are predicted to attain a 50/50 likelihood based on these variables and almost none of the women are predicted to have less than a 50/50 chance. 
Table (4): Logistic Regression Analyses of Harassment in the Military for Female Respondents

Overall Harassment

Individual Harassment

Environmental Harassment

Black
Hispanic
Other
Officer
First Enlist.
Married
Army
Navy
Marines
Coast Guard
Black Officer
Hispanic Officer
Other Officer
Constant

\begin{tabular}{l} 
Coeff. \\
\hline$-0.48^{* * *}$ \\
-0.13 \\
-0.16 \\
-0.04 \\
$0.44^{* * *}$ \\
$-0.33^{* * *}$ \\
$0.56^{* * *}$ \\
$0.53^{* * *}$ \\
$0.65^{* * *}$ \\
$0.60^{*}$ \\
0.04 \\
0.31 \\
-0.04 \\
0.02
\end{tabular}

S.E. $\quad \operatorname{Exp}(\mathrm{B})$

$\begin{array}{lllll}\mathrm{R} & \text { Coeff. } & \text { S.E. } & \operatorname{Exp}(\mathrm{B}) \quad \mathrm{R}\end{array}$

Coeff. S.E. $\operatorname{Exp}(B) \quad R$

0.10

0.62

$0.07 \quad-0.35$

$-0.35^{* * *} \quad 0.10$

\begin{tabular}{ll|l}
0.71 & 0.05 & -0.2
\end{tabular}

\begin{tabular}{llll}
$-0.44^{* * *}$ & 0.10 & 0.64 & 0.07 \\
-0.17 & 0.14 & 0.84 & 0.00 \\
-0.18 & 0.15 & 0.83 & 0.00 \\
-0.01 & 0.14 & 0.99 & 0.00 \\
$0.40^{* * *}$ & 0.09 & 1.49 & 0.07 \\
$-0.28^{* * *}$ & 0.08 & 0.75 & 0.05 \\
$0.56^{* * *}$ & 0.09 & 1.75 & 0.09 \\
$0.56^{* * *}$ & 0.10 & 1.76 & 0.09 \\
$0.79^{* * *}$ & 0.19 & 2.20 & 0.06 \\
$0.66^{*}$ & 0.28 & 1.93 & 0.03 \\
0.02 & 0.28 & 1.02 & 0.00 \\
0.32 & 0.42 & 1.38 & 0.00 \\
-0.19 & 0.37 & 0.83 & 0.00 \\
-0.17 & 0.10 & 0.85 & \\
\hline
\end{tabular}

Model Chi-Square $(\mathrm{df}=13)$

Cox \& Snell R Square

0.14

\begin{tabular}{lll|l}
0.87 & 0.00 & -0.04
\end{tabular}

0.14

0.96

1.05

0.15

0.85

0005

0.15

1.05

0.17

0.59

0.14

0.96

$0.00-0.52^{* * *}$

0.09

1.84

0.65

0.08

0.10

$\begin{array}{llll}0.72 & 0.06 & -0.44 * * *\end{array}$

0.08

0.10

1.77

0.10

1.75

$0.090 .57^{* * *}$

0.08

0.19

0.29

$0.050 .49^{* * *}$

0.11

1.64

0.19

1.64

1.92

1.82

$0.02 \quad 0.30$

\begin{tabular}{llll|l}
0.28 & 1.04 & 0.00 & 0.08
\end{tabular}

0.30

1.35

0.35

1.08

0.47

0.42

1.36

$0.00 \quad 0.32$

0.36

0.96

$0.00 \quad 0.11$

0.10

1.02

$-0.87^{* * *}$

0.42

0.11

1.38

1.12

199.06***

$128.92^{* * *}$

\subsection{6}

0.067

0.044

0.062

0.092

0.058

\section{Percent Correct}

Overall

60.583

65.615

59.392

38.942

90.343

55.049

Some Harassment

77.853

20.264

63.411 
Table (5): Logistic Regression Analyses of Harassment in the Military for Male Respondents

\begin{tabular}{|c|c|c|c|c|c|c|c|c|c|c|c|c|}
\hline & \multicolumn{4}{|c|}{ Overall Harassment } & \multicolumn{4}{|c|}{ Individual Harassment } & \multicolumn{4}{|c|}{ Environmental Harassment } \\
\hline & Coeff. & S.E. & $\operatorname{Exp}(B)$ & $\mathrm{R}$ & Coeff. & S.E. & $\operatorname{Exp}(B)$ & $\mathrm{R}$ & Coeff. & S.E. & $\operatorname{Exp}(B)$ & $\mathrm{R}$ \\
\hline Black & $0.10 *$ & 0.05 & 1.11 & 0.01 & 0.00 & 0.07 & 1.00 & 0.00 & $0.09 \dagger$ & 0.05 & 1.10 & 0.01 \\
\hline Hispanic & $0.16^{* *}$ & 0.06 & 1.18 & 0.02 & $0.27^{* * *}$ & 0.07 & 1.31 & 0.03 & $0.15^{*}$ & 0.06 & 1.16 & 0.01 \\
\hline Other & 0.09 & 0.06 & 1.09 & 0.00 & 0.07 & 0.08 & 1.07 & 0.00 & $0.11 \dagger$ & 0.07 & 1.12 & 0.01 \\
\hline Officer & $-0.15^{*}$ & 0.06 & 0.86 & 0.01 & $-0.77 * * *$ & 0.11 & 0.47 & 0.06 & $-0.11 \dagger$ & 0.06 & 0.89 & 0.01 \\
\hline First Enlist. & $0.29 * * *$ & 0.04 & 1.34 & 0.05 & $0.47^{* * *}$ & 0.06 & 1.60 & 0.07 & $0.23 * * *$ & 0.04 & 1.26 & 0.04 \\
\hline Married & $-0.22 * * *$ & 0.04 & 0.81 & 0.04 & $-0.47 * * *$ & 0.05 & 0.62 & 0.08 & $-0.17 * *$ & 0.04 & 0.85 & 0.03 \\
\hline Army & $0.14^{* *}$ & 0.05 & 1.15 & 0.02 & 0.06 & 0.07 & 1.07 & 0.00 & $0.17 * *$ & 0.05 & 1.18 & 0.02 \\
\hline Navy & $0.17^{* * *}$ & 0.05 & 1.19 & 0.02 & $0.25^{* * *}$ & 0.07 & 1.29 & 0.03 & $0.19 * *$ & 0.05 & 1.21 & 0.02 \\
\hline Marines & 0.01 & 0.06 & 1.01 & 0.00 & $0.17^{*}$ & 0.08 & 1.19 & 0.01 & -0.04 & 0.07 & 0.96 & 0.00 \\
\hline Coast Guard & $0.36^{* * *}$ & 0.11 & 1.43 & 0.02 & 0.16 & 0.16 & 1.17 & 0.00 & $0.38^{* * *}$ & 0.11 & 1.47 & 0.02 \\
\hline Black Officer & 0.07 & 0.18 & 1.07 & 0.00 & -0.29 & 0.41 & 0.75 & 0.00 & 0.12 & 0.19 & 1.13 & 0.00 \\
\hline Hisp. Officer & 0.09 & 0.21 & 1.09 & 0.00 & 0.35 & 0.32 & 1.42 & 0.00 & 0.08 & 0.21 & 1.08 & 0.00 \\
\hline Other Officer & -0.12 & 0.22 & 0.89 & 0.00 & 0.07 & 0.38 & 1.07 & 0.00 & -0.11 & 0.22 & 0.89 & 0.00 \\
\hline Constant & -1.07 & 0.05 & 0.34 & & -1.97 & 0.07 & 0.14 & & -1.21 & 0.06 & 0.30 & \\
\hline Model Chi-Square $(\mathrm{df}=13)$ & \multicolumn{4}{|c|}{$210.64^{* * *}$} & \multicolumn{4}{|c|}{$497.98 * * *$} & \multicolumn{4}{|c|}{$143.8^{* * *}$} \\
\hline Cox \& Snell R Square & \multicolumn{4}{|c|}{0.013} & \multicolumn{4}{|c|}{0.031} & \multicolumn{4}{|c|}{0.009} \\
\hline Nagelkerke R Square & \multicolumn{4}{|c|}{0.019} & \multicolumn{4}{|c|}{0.058} & \multicolumn{4}{|c|}{0.013} \\
\hline \multicolumn{13}{|l|}{ Percent Correct } \\
\hline Overall & \multicolumn{4}{|c|}{72.341} & \multicolumn{4}{|c|}{87.533} & \multicolumn{4}{|c|}{74.777} \\
\hline No Harassment & \multicolumn{4}{|c|}{100.000} & \multicolumn{4}{|c|}{100.000} & \multicolumn{4}{|c|}{100.000} \\
\hline Some Harassment & \multicolumn{3}{|c|}{0.000} & & \multicolumn{3}{|c|}{0.000} & & \multicolumn{4}{|c|}{0.000} \\
\hline
\end{tabular}


Finally, Table 6 presents results comparing those who report both environmental and individual harassment experiences. The results are an important replication of our earlier published work documenting that when environmental harassment is not reported, individual harassment is extremely rare (Firestone \& Harris, 1994; Firestone \& Harris, 1999).

\begin{tabular}{|l|ccc|}
\hline \multirow{2}{*}{ Table (6): Individual by Environmental Harassment } \\
\cline { 2 - 4 } & \multicolumn{3}{c|}{ Environmental } \\
\cline { 2 - 4 } Individual & None & Some & Total \\
\cline { 2 - 4 } None & \multicolumn{3}{|c|}{ Males } \\
Some & 96.7 & 59.5 & 87.3 \\
Total & 3.3 & 40.5 & 12.7 \\
$\mathrm{~N}$ & 100.0 & 100.0 & 100.0 \\
& 12087 & 4066 & 16153 \\
None & \multicolumn{3}{|}{ Females } \\
Some & 91.8 & 37.7 & 63.7 \\
Total & 8.2 & 62.3 & 36.3 \\
N & 100.0 & 100.0 & 100.0 \\
\hline
\end{tabular}

\section{Discussion}

The initial objective of this research was to test for double jeopardy in the sexual harassment experiences reported by minority women. The results do not support the double jeopardy expectation. In fact, Black women are significantly less likely to report any form of sexual harassment, and Hispanic women were significantly less likely to report environmental harassment, but not significantly related to reporting ever being harassed or individual harassment. None of the other variables in the logistic equations that focus on the interaction of sex and race are statistically significant. This finding stands in contrast to conclusions from other research. For example, Fain and Anderton (1987) report that minority women are among the primary targets of sexual harassment. The lower level of reported harassment for Black women may reflect an historical and cultural context in which the same behaviors identified as harassment by White women are not viewed as uninvited or unwanted by Black women (Staples, 1994). It may be the case that experiences of racial harassment are more likely noticed by these women than sexual harassment. Nevertheless, it must be remembered that about half of the black women stated that they experienced some sexual harassment, with about one third identifying individual harassment experiences.

Additionally, we found no support for the "biological/natural" model of harassment. The general prevalence of harassment behaviors denies the thesis that it is atypical and random. Among the crucial findings is that all women were still likely to report being harassed, and that men are increasingly likely to report harassment experiences. Married men and women were less likely to report harassment experiences. Service branch has no significant bearing on reporting of harassment by women, but men in the Army, Navy and Marines were more 
likely to report all types of harassment, while male Coast Guard members were significantly likely to report ever-being harassed and experiencing environmental harassment. The substantial differences between service branches for men suggest the importance of organizational context in producing different levels of harassment. Furthermore it may be the case that individual statuses (such as being married) and organizational context may play new roles in shaping the likelihood of labeling and reporting experiences as sexual harassment.

Our findings clearly contradict prevailing ideas related to double jeopardy. While among all respondents, Blacks, Hispanics and women were more likely to report harassment experiences, the only significant sex-race/ethnic interaction coefficients were in the opposite direction. Among female respondents, minority members were LESS likely to report harassment. However among male respondents, Blacks and Hispanics were significantly more likely to report harassment. The cultural model would suggest that our findings that minority women are less likely to report harassment might result from differences in subjective interpretation of harassment based on the race of the individuals involved. In other words, racial prejudice or stereotypes may foster perceptions of sexual harassment (DeFour, 1990; Staples, 1994). This argument suggests that Black women would be less likely to perceive harassment from Black men (same race) because the men's behavior would be defined as courtship. White women would be more likely to perceive cross-race harassment because black men's behaviors would be seen as harassment rather than as "courting” behavior. We hope to complete further analyses to help unravel these complex issues.

Our findings do not provide strong support for cultural models which attempt to explain differences in sexual harassment by race and ethnicity. In spite of the fact that Black women were significantly less likely to report experiencing uninvited, unwanted sexual behaviors, half of the Black women, and even higher percentages of Hispanics and women of "other" races report such experiences. Even focusing on individual harassment, nearly one third of the Black women still reported such occurrences. Indeed men report substantially higher levels of all types of harassment than in the two previous surveys, although it is not yet clear whether this may be a result of the new measurement approach adopted in for the 2002 survey.

Most importantly, our results reinforce earlier conclusions by Firestone and Harris (1994; 1999) that the environmental context of sexual harassment must be controlled in shaping the organizational culture. As in the earlier work, results from these data very clearly illustrate that when individuals perceived no environmental harassment, virtually no individual harassment was reported.

\section{References}

Aldrich, J. H. \& Nelson, F. D. (1984). Linear probability, logit and probit models. Beverly Hills, CA: Sage Publications.

Almquist, E. M. (1975). Untangling the effects of race and sex: The disadvantaged status 
of black women. Social Science Quarterly, 56, 129-142.

Almquist, E. M. (1979). Minorities, gender and work. Lexington MA: D.C. Heath \& Co.

Butler, J. S. \& Brewer, R. M. (1978). The promotion of enlisted women in the military. Armed Forces and Society, 4, 679-688.

Cockburn, C. (1991). In the way of women. Ithaca, NY: ILR Press.

Colatosti, C. \& Karg, E. (1991). Stopping sexual harassment. Detroit: Labor Education and Research Project.

Culbertson, A. L., Rosenfeld, P., Booth-Kewley, S., \& Magnusson, P. (1992). Assessment of sexual harassment in the Navy: Results of the 1989 Navy-wide survey, TR-92-11. San Diego, CA: Navy Personnel Research and Development Center.

Culbertson, A. L., Rosenfeld, P., \& Newell, C. E. (1993). Sexual harassment in the active-duty Navy; Findings from the 1991 Navy-Wide survey, TR-94-2. San Diego, CA: Navy Personnel Research and Development Center.

Defnse Manpower Data Center (DMDC). (2003). Status of the armed forces surveys: Workplace and gender relations (Forms 2002GB). DMDC Survey No. 02-0001, Arlington, VA: DMDC.

DeFour, D. (1990). The interface of racism and sexism on college campuses. In M. Paludi (Ed.) Ivory power: Sexual harassment on campus (pp. 49-56). Albany: State University of New York.

Departent of Defense (1988). Report of the task force on women in the military. Washington, D.C.: U.S. Government Printing Office.

DiTomaso, N. (1989). Sexuality in the workplace: Discrimination and harassment. Pp. 71-90 In J. Hearn, D. L. Sheppard, P. Tancred-Sheriff \& G. Burrell (Eds.). The Sexuality of Organization (pp. 71-90). London: Sage.

Elig, T. W. (2003). Sampling design for the 2202 status of the Armed Forces surveys Workplace and Gender Relations,” In B. J. George and K. R. Kroeger (Eds.) 2002 status of the Armed Forces surveys - Workplace and gender relations: Statistical methodology report, Report No. 2003-014). Arlington, VA: Defense Manpower Data Center.

Fagenson, E. A. (1993). Women in Management: Trends, issues, and challenges in managerial diversity. Newbury Park, CA: Sage.

Fain, T. C. and Anderton, D. L. (1987). Sexual harassment: Organizational context and diffuse Status. Sex Roles, 17, 291-311.

Farley, L. (1978). Sexual shakedown: The sexual harassment of women on the job. San Francisco, McGraw-Hill.

Farmer, M. M. \& Ferraro, K. F. (2005). Are racial disparities in health conditional on socioeconomic status? Social Science and Medicine, 60, 191-204. 
Firestone, J. M. \& Harris R. J. (1994). Sexual harassment in the U.S. Military: Individualized and environmental contexts. Armed Forces \& Society, 21, 25-43.

Firestone, J. M. \& Harris R. J. (1999). Changes in patterns of sexual harassment in the U.S. Military: A comparison of the 1988 and 1995 DoD surveys, Armed Forces \& Society, 25, 613-632.

Firestone, J. M. \& Harris R. J. (2004). Perceptions of effectiveness of responses to sexual harassment in the U.S. Military, 1988 and 1995. Gender, work and organization, 10, 42-64.

Fitzgerald, L. F. (1990). Sexual harassment: The definition and measurement of a construct. In M. A. Paludi (Ed.). Ivory power: Sexual harassment on campus (pp. 25-48). Albany: State University of New York.

Fitzgerald, L. F. \& Shullman, S. L. (1993). Sexual harassment: A research analysis and agenda for the 1990s. Journal of Vocational Behavior, 35, 309-326.

Flores-Cervantes, I., Valliant, R., Harding, L., \& Bell, B. (2003). Weighting for the 2002 status of the Armed Forces surveys - Workplace and Gender Relations,” In B. J. George and K. R. Kroeger (Eds.) 2002 status of the Armed Forces surveys - Workplace and gender relations: Statistical methodology report, Report No. 2003-014. Arlington, VA: Defense Manpower Data Center.

Frug, M. J. (1992). Women and the law. Westbury NY: The Foundation Press, Inc.

Foegen, J. H. (1992). The double jeopardy of sexual harassment. Business and Society Review, 82, 31-35.

Giuffre, P. A. \& Williams C. L. (1997). Boundary lines: Labeling sexual harassment in restaurants. In M. B. Zinn, P. Hondagnew-Sotelo \& M. A. Messner (Eds.) Through the prism of difference: Readings on sex and gender (pp. 372-387). Boston: Allyn and Bacon.

Gruber, J. E. \& Bjorn, L. (1986). Women's responses to sexual harassment: An analysis of sociocultural, organizational and personal resource models. Social Science Quarterly, 29, 814-826.

Gutek, B. A. \& Morasch, B. (1982). Sex-ratios, sex-role spillover, and sexual harassment of women at work. Journal of Social Issues, 38, 55-74.

Harris, R. J. \& Firestone, J. M. (1997). Subtle sexism in the U.S. Military: Individual responses to sexual harassment. In N. V. Benokraitis (Ed.), Subtle sexism: Current practice and prospects for change (pp. 154-171). Thousand Oaks, CA: Sage Publications.

Harris, R. J. \& Firestone, J. M. (1996). Testing for the interaction of race and sex: Sexual harassment in the U.S. Military, National Journal of Sociology, XX, 1-19.

Jackson, R. A. \& Newman, M. A. (2004). Sexual harassment in the federal workplace revisited: Influences on harassment by gender, Public Administration Review, 64, 705-717.

Kasinsky, R.G. (1992). Sexual harassment: A health hazard for women workers. New 
Solutions, 2, 74-83.

King, D. K. (1988). Multiple jeopardy, multiple consciousness: The context of a black feminist ideology. Signs, 14, 42-72.

Konrad, A. M. \& Gutek B. A. (1986). Impact of work experiences on attitudes towards sexual harassment, Administrative Science Quarterly, 31, 422-438.

Lipari, R. N. \& Lancaster A. R. (2003). Armed forces 2002 sexual harassment survey, DMDC Report No., 2003-026, Arlington, VA: Defense Manpower Data Center.

MacKinnon, C. A. (1979). Sexual harassment of working women. New Haven, CT: Yale.

Malveaux, J. \& Wallace, P. (1987). Minority women in the workplace. In K. Koziara, M.

Moskow, \& L. Tanner (Eds.), Women and work: Industrial relations research association research volume. Washington, D.C.: Bureau of National Affairs.

Martinale, M. (1990). Sexual harassment in the military: 1988. Arlington, VA: Defense Manpower Data Center.

Martinale, M. (1991). Sexual harassment in the military: 1988. Sociological Practice Review, 2(3), 200-216.

Murrel, A. L. (1996). Sexual harassment and women of color: Issues, challenges, and future directions. In M. S. Stockdale (Ed.), Sexual harassment in the workplace; Perspectives, frontiers, and response strategies (pp. 51-66). Thousand Oaks, CA: Sage.

Newman, M. A., Jackson, R. A., \& Baker, D. D. (2003). Sexual harassment in the federal workplace. Public Administration Review, 63(4), 472-483.

Niebur, R. E. \& Boyles, W. R. (1991). Sexual harassment of military personnel, International Journal of Intercultural Relations, 15, 445-457.

Norusis, M. J. (1990). SPSS advanced statistics student guide. Chicago, IL: SPSS Inc.

O’Conell, L. (1996). Race and sex discrimination: A Comparison. In P. J. Dubeck \& K. Borman (Eds.), Women and work: A handbook (pp. 300-302). New York: Garland.

Pryor, J. B. (1985). The lay person's understanding of sexual harassment, Sex Roles, 13, 273-286.

Pryor, J. B. (1987). Sexual harassment proclivities in men, Sex Roles, 17, 269-290.

Roman, P. M. (2004). Race and gender differences in workplace autonomy: A research note, Sociological Inquiry, 74, 590-603.

Ryff, C. D., Keyes, C. L., \& Hughes, D. L. (2003). Status inequalities, perceived discrimination, and eudaimonic well-being: Do the challenges of minority life hone purpose and growth?, Journal of Health and Social Behavior, 44(3), 275-291.

Staples, R. (1994). Anita Hill, sexual harassment, and gender politics in the black community. 
In M. B. Zinn, P. Hondagnew-Sotelo, \& M. A. Messner (Eds.), Through the prism of difference: Readings on sex and gender (pp. 186-204). Boston: Allyn and Bacon.

Stewart, J. B. \& Firestone, J. M. (1992). Looking for a few good men: Predicting patterns of retention, promotion, and accession of minority and women officers, The American Journal of Economics and Sociology, 51(4), 435-458.

Segura, D. A. (1992). Walking on eggshells: Chicanas in the labor force. In S. B. Knouse, P. Rosenfeld, \& A. L. Culbertson (Eds.), Hispanics in the Workplace (pp. 173- 193). Newbury Park: Sage.

TangriS. S., Burt, M. R. \& Johnson, L. B. (1982). Sexual harassment at work: Three explanatory models. Journal of Social Issues, 38, 33-54.

Terpstr, D. E. \& Baker, D. D. (1986). Psychological and demographic correlates of perception of sexual harassment. Genetic, Social and General Psychology Monographs, 112, 459-478.

Thomann, D. A. \& Wiener, R. L. (1987). Physical and psychological causality as determinants of culpability in sexual harassment Cases, Sex Roles, 17, 573-591.

Thomas, M. D. (1995). Gender differences in conceptualizing sexual harassment, TR-95-1. San Diego, CA: Navy Personnel Research and Development Center.

Thomas, P. J. (1987). Appraising the performance of women in the U.S. Navy. In B. Gutek \& L. Larwood (Eds.), Women's career development. Beverly Hills, CA: Sage.

Thomas, P. J., Newell, C. E., \& Eliassen, D. M. (1995). Sexual harassment of Navy personnel:Results of a 1993 survey, TN-91-1. San Diego, CA: Navy Personnel Research and Development Center.

Uggen, C. \& Blackstone, A. (2004). Sexual harassment as a gendered expression of power, American Sociological Review, 69, 64-92.

U.S. Merit Systems Protection Board. (1988). Sexual harassment in the federal government: An update. Washington, D.C.: Office of Merit Systems Review and Studies.

Zimmerman, J. (1995). Tail spin: Women at war in the wake of Tailhook. New York: Doubleday.

\footnotetext{
i While men as well as women can experience sexual harassment, research to date indicates women are the more likely targets.

ii Many authors refer to "triple jeopardy" referring to the interactions of race, class and gender.

iii Because the questions used in the 2002 survey were not an exact match to the questions from the original 1988 survey, our conceptualizations for individual and environmental harassment are a broad match, but not an exact match of our earlier research. For a description of the statements classified as individual or environmental harassment, see Firestone and Harris, 1994).
} 